\title{
Expression of epidermal growth factor receptor (EGFR) in cholangiocarcinomas: predictive factors and survival
}

\section{Expressão do receptor do fator de crescimento epitelial (EGFR) em colangiocarcinomas: fatores preditivos e sobrevida}

Rodrigo Vieira Gomes'; Michele Ângela Rodrigues²; João Bernardo Sancio Rocha Rodrigues, ACbC-MG'; Paula Teixeira Vidigal; Karine Araújo Damasceno²; Henrique Araújo lima ${ }^{1}$; Damidson Assis Gomes ${ }^{4}$; Carla Jorge Machado5; ${ }^{5}$ Vivian Resende, TCBC-MG ${ }^{1}$

\section{A B S T R A C T}

\begin{abstract}
Objective: to evaluate the expression of the epithelial growth factor receptor (EGFR) by immunohistochemistry, and to verify its association with prognostic factors and survival of patients operated by cholangiocarcinoma. Methods: we verified the immunohistochemical expression of EGFR in 35 surgical specimens of cholangiocarcinoma (CCA). We obtained survival curves with the Kaplan-Meier method. Results: we found significant EGFR expression in ten (28.6\%) of the 35 CCAs, eight with score 3 and two with score 2. Advanced stages (III and IV) presented higher EGFR expression ( $(=0.07$ ). The clinical characteristics that were most associated with positive EGFR expression were female gender $(p=0.06$ ) and absence of comorbidities ( $p=0.06)$. Overall survival at $12,24,36$ and 48 months was $100 \%, 82.5 \%, 59 \%$ and $44.2 \%$, respectively. The survival of EGFR positive patients at 12, 24, 36 and 48 months was $100 \%, 75 \%, 50 \%$ and $0 \%$, whereas for negative EGFR patients it was $100 \%, 87.5 \%, 65.6 \%$ and $65.6 \%$, respectively. Conclusion: EGFR expression occurred in $28.6 \%$ of the cases studied and was associated with lower survival.
\end{abstract}

Keywords: Cholangiocarcinoma. Genes, erbB-1. Prognosis. Survival Analysis.

\section{INTRODUCTION}

C holangiocarcinoma (CCA) is the second most frequent primary malignant neoplasm in the liver and accounts for about 3\% of all gastrointestinal cancers $^{1}$. It originates from the epithelium of intra or extrahepatic bile ducts ${ }^{2}$. It has been described by Durand-Fardel for the first time in 1840, and can be divided according to its location into intrahepatic, perihilar (Klatskin tumor) and distal ${ }^{3}$. Histologically, it is usually an adenocarcinoma and displays varying degrees of differentiation and phenotypes ${ }^{4}$. Some risk factors for cholangiocarcinoma have already been established, such as parasitic infections, primary sclerosing cholangitis, bile duct cysts, hepatolithiasis, and some toxins. Other potential risk factors include inflammatory bowel disease, hepatitis B and C virus, liver cirrhosis, diabetes mellitus, obesity, alcoholism, smoking, and genetic mutations ${ }^{5}$. The incidence of CCA has been increasing in recent years ${ }^{6}$.

More attention has been devoted to CCA due to poor prognosis, coupled with the poor efficacy of therapeutic modalities, especially for patients with advanced disease ${ }^{7}$. Chemotherapy has been widely used, though with a low response rate ${ }^{7,8}$. Staging, size and degree of tumor differentiation, resection

1 - Faculty of Medicine, Surgery Department, Federal University of Minas Gerais, Belo Horizonte, MG, Brazil. 2 - Institute of Biological Sciences, General Pathology, Federal University of Minas Gerais, Belo Horizonte, MG, Brazil. 3 - Faculty of Medicine, Pathological Anatomy and Legal Medicine, Federal University of Minas Gerais, Belo Horizonte, MG, Brazil. 4 - Institute of Biological Sciences, Biochemistry and Immunology, Federal University of Minas Gerais, Belo Horizonte, MG, Brazil. 5 - Faculty of Medicine, Preventive and Social Medicine, Federal University of Minas Gerais, Belo Horizonte, MG, Brazil. 
margins, and perineural and angiolymphatic invasion are described as prognostic factors 9 . Among the factors that contribute to poor prognosis, the advanced stage of the disease is highlighted, which decreases the chance of cure by surgical treatment ${ }^{10}$. More than $50 \%$ of the cases are diagnosed at an advanced stage, leading to a general average survival of approximately seven to eight months ${ }^{10}$. Patients who undergo surgical resection have a better prognosis, with a five-year survival rate of $30 \%$ and mean survival of 30 months ${ }^{11-13}$.

Epidermal growth factor receptor (EGFR) is a cell membrane receptor tyrosine kinase encoded by proto-oncogenes. Different ligands, such as epidermal growth factor (EGF), heparin binding factor (HB-EGF), and amphiregulin, couple in the extracellular domains of these receptors and initiate an intracellular signaling cascade, increasing the potential for cell proliferation, angiogenesis and resistance to apoptosis. EGFR activation also impairs cell-cell adhesion through the destabilization of junctional complexes (E-cadherin, beta-catenin), which contributes to the acquisition of motile and invasive phenotype $^{14,15}$.

Epidermal growth factor inhibitors, antibodies and other molecules, such as erlotinib, gefitinib, cetuximab, panitumumab, trastuzumab and lapatinib, have been used in the treatment of colorectal, breast, lung and head and neck cancers, with promising results, having as targets the EGFR or the human epidermal growth factor receptor 2 (HER2) ${ }^{11,16}$. The overexpression of EGFR in tumor cells was associated with a worse prognosis in some studies, being found in up to $80 \%$ of the cholangiocarcinomas, making this receptor a potential therapeutic target in patients with this type of neoplasia16-19.

The role of EGFR in malignant liver diseases is still poorly understood. The identification of groups of patients with more aggressive subtypes and risk of lower survival could contribute to the development of more effective therapeutic options. To better understand the clinical significance of EGFR in cholangiocarcinoma, the main objectives of the present study were to evaluate the degree of immunohistochemical expression of EGFR and to verify its association with clinical-pathological factors and survival of patients submitted to surgical treatment.

\section{METHODS}

This research was approved by the Institutional Ethics Committee with the following reference number: CAAE - 37156714.6.0000.5149. From January 2008 to December 2015, we selected patients undergoing surgical treatment and histological diagnosis of cholangiocarcinoma. We collected data regarding gender, age, previous history, history of smoking or alcoholism, presence of gallstones, family history for neoplasia, histological type, tumor staging and survival after treatment. The laboratory tests analyzed were bilirubins and Ca 19-9. The classification of the anatomical location of the tumors and the staging were based on the description of the radiological studies (Computed Tomography, Magnetic Resonance and/ or Magnetic Resonance Cholangiopancreatography) associated with the findings of the surgical description and anatomopathological study. We revised the hematoxylin and eosin (HE) stained slides to classify tumors as polypoid and non-polypoid. Classification and staging followed the TNM pattern of the American Joint Cancer Committee/Union for International Cancer Control - 7th edition ${ }^{20,21}$.

We included patients whose tissue samples were obtained from surgical resection specimens or surgical biopsies of cholangiocarcinomas. Samples of gallbladder cancer and the hepatopancreatic (Vater's) ampulla and cases of biopsies in which the material was insufficient for analysis (six cases) were considered exclusion criteria. All samples were fixed in 10\% formaldehyde, embedded in paraffin, cut into fragments with a thickness of four micrometers and stained with hematoxylin and eosin.

We performed the histological and immunohistochemical analysis in tissues representative 
of the primary tumor site, consisting of 30 specimens of surgical resection with curative intent and five biopsies. The slides were initially processed with pepsin and hydrochloric acid at $37^{\circ} \mathrm{C}$ for 30 minutes for antigen retrieval and, thereafter, blocking of endogenous peroxidase and proteins. Next, incubation with the primary antibody (EGFR - clone 3G7 - Invitrogen 1:100 dilution) was performed for 16 to 18 hours (overnight incubation). Thereafter, the antibody was removed, the polymer was placed and the slides were incubated in the humid chamber for 30 minutes at room temperature. After removal of the polymer, the chromogen 3,3' Diaminobenzidine tetrahydrochloride (DAB), which was withdrawn after the reaction. When the reaction was positive, brown staining was observed at the antigen site. Then, we performed HE counterstaining and assembled the slides with transparent medium.

All slides were evaluated by a pathologist with experience in immunohistochemical analysis, without prior knowledge of the clinical and pathological information of the patients. The intensity of EGFR expression was defined according to the previously described score, based on the work of Yoshikawa et al. 22 :

- 0: no staining of the cell membrane or staining of the membrane in $10 \%$ or less of the tumor cells;

- 1+: weak and partial staining of the membrane in more than $10 \%$ of tumor cells;

- $\mathbf{2 +}$ : moderate and complete staining of the membrane in more than $10 \%$ of tumor cells;

- 3+: strong and complete staining of the membrane in more than $10 \%$ of tumor cells.
In cases with variable intensity, the predominant intensity was selected for the final score. Scores $2+$ and $3+$ were defined as positive for protein expression.

We performed statistical analysis using the statistical package Stata for Mac 2016. To compare the distribution of the categories of the study variables according to EGFR expression (negative and positive), we performed the Student's t-test for the continuous variables and Chi-square or Fisher's test for categorical ones. Survival analysis had as the dependent variable the occurrence of death in relation to time, which was measured in months. We excluded cases of death of patients occurring within 30 postoperative days. We constructed survival curves for the variables using the Kaplan-Meier method. In the comparison between groups for each variable, we used the Logrank test. In all analyzes, the level of significance considered was $5 \%$ $(p<0.05)$.

\section{RESULTS}

There was no significant difference in the proportion between men $(n=17)$ and women $(n=18)$. The mean patients' age was 58 years, ranging from 28 to 83 . There were lower proportions of smokers, alcohol users and gallstones (Table 1).

The following procedures with curative intent were performed in 30 patients: eight $(26.66 \%)$ right hepatectomies, two $(6.66 \%)$ right trisegmentectomies and nine (30\%) left hepatectomies, associated with resection of segment one, four (13.33\%) bisegmentectomies (three including segments two and three and one including segments six and seven). Six (20\%) pancreatoduodenectomies and one (3.33\%) resection of the extrahepatic biliary tract were also performed. 
Table 1. Expression of EGFR according to the clinicopathological variables.

\begin{tabular}{|c|c|c|c|c|}
\hline \multirow[b]{2}{*}{ Variables } & \multicolumn{2}{|c|}{ EGFR } & \multirow{2}{*}{$\begin{array}{c}\text { Total } \\
35(100.0)\end{array}$} & \multirow{2}{*}{$\begin{array}{c}\text { Valor } p \\
0.017\end{array}$} \\
\hline & $\begin{array}{c}\text { Negative } \\
(n=25 ; 71.4 \%)\end{array}$ & $\begin{array}{c}\text { Positive } \\
(n=10 ; 28.6 \%)\end{array}$ & & \\
\hline $\begin{array}{l}\text { Age } \\
\text { (mean; SD) }(n=35)\end{array}$ & $59.5(12.6)$ & $56.2(13.7)$ & & 0.496 \\
\hline \multicolumn{5}{|l|}{ Gender (n; \%) } \\
\hline Male & $15(88.2)$ & $2(11.8)$ & $17(100.0)$ & \multirow[t]{2}{*}{0.060} \\
\hline Female & $10(55.6)$ & $8(44.4)$ & $18(100.0)$ & \\
\hline \multicolumn{5}{|l|}{ Smoking (n; \%) } \\
\hline No & $14(63.6)$ & $8(36.4)$ & $22(100.0)$ & \multirow[t]{2}{*}{0.440} \\
\hline Yes & $8(80.0)$ & $2(20.0)$ & $10(100.0)$ & \\
\hline \multicolumn{5}{|l|}{ Alcohol use (n; \%) } \\
\hline No & $17(65.4)$ & $9(34.6)$ & $26(100.0)$ & \multirow[t]{2}{*}{0.637} \\
\hline Yes & $5(83.3)$ & $1(16.7)$ & $6(100.0)$ & \\
\hline \multicolumn{5}{|l|}{ Comorbidities (n; \%) } \\
\hline No & $10(55.5)$ & $8(44.5)$ & $18(100.0)$ & \multirow[t]{2}{*}{0.070} \\
\hline Yes & $13(86.7)$ & $2(13.3)$ & $15(100.0)$ & \\
\hline \multicolumn{5}{|l|}{ Family history (n; \%) } \\
\hline No & $10(71.4)$ & $4(28.6)$ & $14(100.0)$ & \multirow[t]{2}{*}{0.683} \\
\hline Yes & $7(58.3)$ & $5(41.7)$ & $12(100.0)$ & \\
\hline \multicolumn{5}{|l|}{ Biliary lithiasis (n; \%) } \\
\hline No & $17(65.4)$ & $9(34.6)$ & $26(100.0)$ & \multirow[t]{2}{*}{0.637} \\
\hline Yes & $5(83.3)$ & $1(16.7)$ & $6(100.0)$ & \\
\hline \multicolumn{5}{|l|}{ Classification (n; \%) } \\
\hline Intra-hepatic & $6(60.0)$ & $4(40.0)$ & $10(100.0)$ & \multirow{3}{*}{0.185} \\
\hline Peri-hilar & $15(83.3)$ & $3(16.7)$ & $18(100.0)$ & \\
\hline Distal & $4(57.1)$ & $3(42.9)$ & $7(100.0)$ & \\
\hline \multicolumn{5}{|l|}{ CA $19-9(n ; \%)$} \\
\hline$>37 \mathrm{U} / \mathrm{ml}$ & $5(55.5)$ & $4(44.4)$ & $9(100.0)$ & \multirow[t]{2}{*}{0.999} \\
\hline$<37 \mathrm{U} / \mathrm{ml}$ & $8(61.5)$ & $5(38.5)$ & $13100.00)$ & \\
\hline \multicolumn{5}{|l|}{ Bilirubin (n; \%) } \\
\hline $0-4 \mathrm{mg} / \mathrm{dl}$ & $8(57.1)$ & $6(42.9)$ & $14(100.0)$ & \multirow{3}{*}{0.151} \\
\hline $4-10 \mathrm{mg} / \mathrm{dl}$ & $5(71.4)$ & $2(28.6)$ & $7(100.0)$ & \\
\hline$>10 \mathrm{mg} / \mathrm{dl}$ & $8(88.8)$ & $1(11.1)$ & $9(100.0)$ & \\
\hline \multicolumn{5}{|l|}{ Treatment (n; \%) } \\
\hline Palliative & $4(80.0)$ & $1(20.0)$ & $5(100.0)$ & .999 \\
\hline Resection & $21(70.0)$ & $9(30.0)$ & $30(100.0)$ & \\
\hline$T(n ; \%)$ & & & & \\
\hline $1-2$ & $15(83.3)$ & $3(16.7)$ & $18(100.0)$ & 0.146 \\
\hline $3-4$ & $10(58.8)$ & $7(41.2)$ & $17(100.0)$ & \\
\hline $\mathrm{N}$ & & & & \\
\hline Negative & $15(75)$ & $5(25)$ & $20(100)$ & 0.331 \\
\hline Positive & $6(60)$ & $4(40)$ & $10(100)$ & \\
\hline Staging (n; \%) & & & & \\
\hline$|-| \mid$ & $14(87.5)$ & $2(12.5)$ & $16(100.0)$ & 0.071 \\
\hline III-IV & $11(57.9)$ & $8(42.1)$ & $19(100.0)$ & \\
\hline Type of growth (n; \%) & & & & \\
\hline Polypoid & $12(70.6)$ & $5(29.4)$ & $17(100.0)$ & 0.999 \\
\hline Non-polypoid & $13(72.2)$ & $5(27.7)$ & $18(100.0)$ & \\
\hline
\end{tabular}


Table 1 shows the EGFR expression in relation to the variables of interest in the 35 CCA cases. There was significant EGFR expression in ten $(28.6 \%)$ of the 35 lesions, being score $3+$ in eight patients and $2+$ in two patients. In 25 patients (71.4\%), EGFR expression was negative, being $1+$ in five patients and 0 in 20 patients.
The clinical characteristics of patients who had the greatest association with positive expression were female $(p=0.06)$ and absence of comorbidities $(p=0.07)$. Regarding TNM staging, those with the more advanced stages III and IV had greater EGFR expression $(p=0.071)$. Figure 1 shows the intensities and scores attributed to the cholangiocarcinomas.
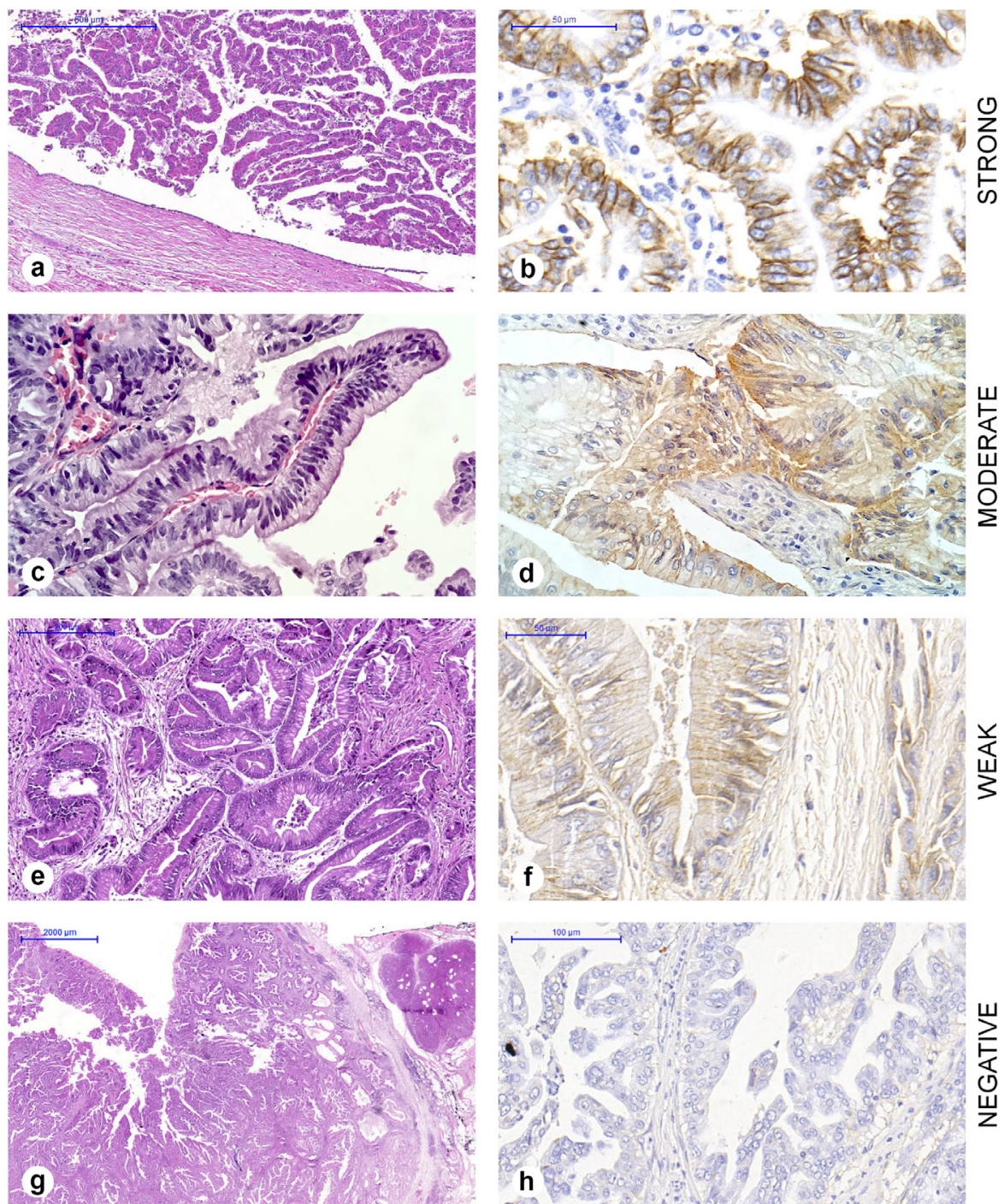

Figure 1. Intensity of EGFR in cholangiocarcinomas. HE staining on the left (a, $c, e, g)$ and EGFR immunohistochemistry on the right (b, $d$, $f$, $h$ ). (b) Complete membrane, strong staining, score 3+. (d) Complete membrane, moderate staining, score 2+. (f) Incomplete membrane, weak staining, score 1+. (h) Negative, score 0.

The overall survival at $12,24,36$ and 48 months was $100 \%, 82.5 \%(\mathrm{Cl}: 45.1-95.5), 59 \%(\mathrm{Cl}: 22.9-82.8)$ and $44.2 \%(\mathrm{Cl}: 11.9-73.2)$, respectively . The survival of patients with EGFR-positive tumors at 12, 24, 36 and 48 months was $100 \%$, 75\% (Cl: 12.8-96.1), 50\% (Cl: 5.8$84.5 \%$ ), and $0 \%$, while of the EGFR-negative patients was $100 \%, 87.5$ (Cl: 38.7-98.1), 65.6\% (Cl: 15.7-90.9) and $65.6 \%(\mathrm{Cl}: 15.7-90.9 \%)$, respectively. The survival of 
patients with EGFR-positive tumors was lower than that of negative EGFR patients, with no statistical significance $(p=0.328)$ (Figure 2).

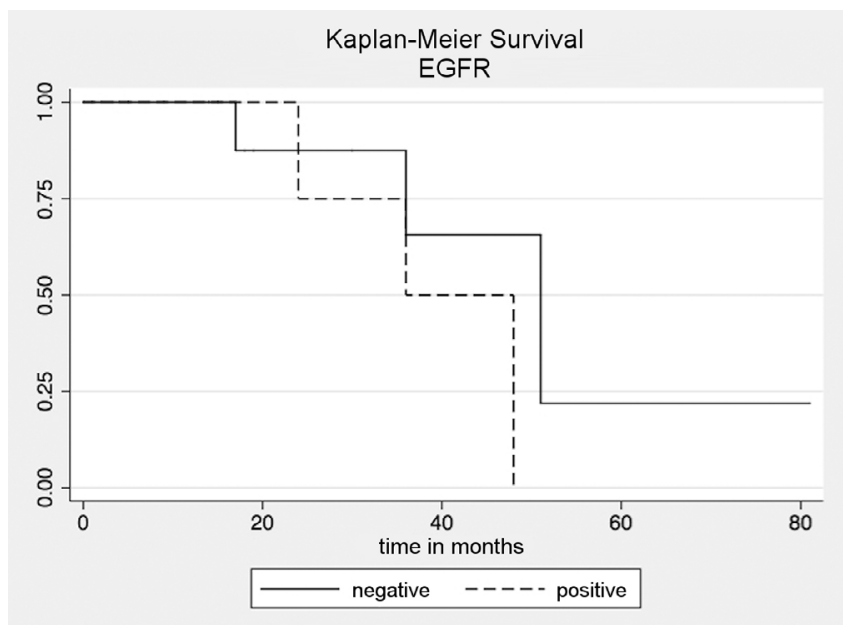

Figure 2. Survival curves obtained by the Kaplan-Meier method $(p=0.328)$ in patients with positive and negative EGFR cholangiocarcinomas.

\section{DISCUSSION}

The expression of ErbB family growth factor receptors, EGFR and HER2 has been studied in different tumor types and has led to the use of targeted therapies with inhibitors or antibodies specific for these receptors in colorectal, breast, lung and head and neck neoplasias ${ }^{16}$. So far, the use of monoclonal antibodies and tyrosine kinase inhibitors, such as cetuximab, trastuzumab, erlotinib, gefitinib, is still being investigated in other types of cancer. In biliary tract cancer, EGFR expression usually occurs in small groups of patients. Yoshikawa et al. recently described the expression of these receptors in malignant tumors of the biliary tract ${ }^{22}$. Harder et al. studied the expression of EGFR and HER2 in a group of patients with advanced and unresectable biliary tract tumors. The results of these authors suggest that routine testing and therapeutic targeting of HER2 does not appear to be useful in patients with bile duct cancer, whereas EGFR may be promising as a target ${ }^{11}$. In a phase II study, Chiorean et al. tested Erlotinib and Docetaxel in hepatocellular carcinoma and advanced cancer of the biliary tract and concluded that for a significant improvement in survival, treatment should probably be individualized according to the tumors' molecular and genetic profiles ${ }^{23}$.

The expression of EGFR in CCA in previous studies occurred with a variability of $8.1 \%$ to $81 \%$, and has been associated with tumors' greater aggressiveness ${ }^{16-19}$. In our study, EGFR expression was considered positive in $28.6 \%$ of the cases and, although there was no statistical significance, we found a higher rate of expression in tumors in advanced stages, occurring in $42.1 \%$ of stages III/IV versus $12.5 \%$ of stages $\mathrm{I} / \mathrm{II}(\mathrm{p}=0.071)$, translating characteristics of aggressive phenotype in the presence of invasive disease. One hypothesis is that the tumor will express more EGFR upon reaching advanced stages. Survival analysis also corroborated the hypothesis that EGFR expression is associated with a worse prognosis, since patients considered positive had lower survival rates than negative ones.

These findings, previously mentioned, can be explained by the work of Clapéron et al., who demonstrated that the EGF/EGFR axis is a potent inducer of the epithelial-mesenchymal transition, one of the main molecular factors associated with the progression of cholangiocarcinoma ${ }^{24}$. It is known that EGFR activation interferes with intercellular adhesion, destabilizing the E-cadherin/beta-catenin complex, promoting the epithelial-mesenchymal transition, which contributes to increase in the capacity of migration, invasion and resistance to apoptosis ${ }^{24,25}$. Similarly, Hoffmann et al. found a worse prognosis in patients with EGFR expression, with an average survival of only 8.5 months, while patients with low expression had a mean survival rate of more than three years ${ }^{17}$. The significant association of EGFR with survival may help to select more effective treatment strategies for patients with CCA.

Our EGFR staining score readings were based on the work of Yoshikawa et al. ${ }^{22}$, who considered complete or incomplete staining of the cytoplasmic membrane. According to Harder et al., tumors were considered negative when less than $10 \%$ of cancer cells were stained, regardless of the intensity in the membrane ${ }^{10}$. In the work of these authors, the expression 
of EGFR was absent in $39.3 \%$ (22/56) of patients, whilst they observed weak expression (1+) in $21.5 \%$ (12/56), moderate $(2+)$ expression in $23.2 \%(13 / 56)$ and intense $(3+)$ in $16 \%(9 / 56)$. The fact that we used a different way to obtain the score may be the reason we obtained results (28.6\%) inferior to those authors'. In addition, Harder et al. ${ }^{11}$ performed biopsy investigations of advanced and unresectable cases of biliary carcinoma without distinguishing between gallbladder carcinoma and bile duct cholangiocarcinoma, whereas we only studied patients with carcinoma of the biliary ducts, and in different stages.

Yoshikawa et al. showed an overexpression in $26.4 \%$ of extrahepatic CCAs and in $17.7 \%$ of intrahepatic CCAs. These authors considered only two anatomic sites, including peri-hilar carcinomas in the extrahepatic CCA group 22 . In our study, we considered peri-hilar carcinoma separately and EGFR expression was only $16.7 \%$ in that group, smaller than in the others. Harder et al. found an expression rate of $57.9 \%$ in the extrahepatic lesions and $25 \%$ in the intrahepatic ones ${ }^{11}$. In our study, expression in extrahepatic CABG was $42.9 \%$. These divergences can be explained by the different ways of anatomical classification adopted, which are still controversial in the literature, especially in relation to extrahepatic cholangiocarcinoma.

Although the World Health Organization (WHO) includes peri-hilar and distal CCAs in the extrahepatic modlity ${ }^{20,21}$, they are known to have different biological behaviors and respond differently to chemotherapy. In a systematic review, Wiggers et al. showed significant differences in the expression of biomarkers between intrahepatic and extrahepatic CCAs, being more relevant in the markers that are potential targets of systemic therapies (EGFR, c-erB-2 and VEGF-A), suggesting that they should be treated as distinct tumors ${ }^{26}$. Ercolani et al. have already classified CCAs into three subgroups (intrahepatic, peri-hilar and extrahepatic) and concluded that CCAs appear to be the same type of tumor, but depending on the location, have different invasion properties of adjacent structures, which may also influence prognosis ${ }^{27}$. Our results corroborate this conclusion, since the anatomical location implied different survival outcomes, although the correlation with EGFR expression displayed no significant difference between the three locations.

Challenges for the development of targeted therapies for CCAs include not only the heterogeneity of these tumors but also the rarity of the cases when compared to other solid tumors and the lack of interest of the pharmaceutical industry ${ }^{19}$. Some limitations may be noted in our study. Conducting the research in a single center limited the size of the sample, since it is a relatively rare disease. This fact may have been responsible for the lack of statistical significance in some of our findings.

We conclude that EGFR expression occurred in a considerable number of cholangiocarcinomas studied and was associated with patient's lower survival rates. Studies with a greater number of cases will be necessary to prove the influence of EGFR expression on the prognosis of patients with cholangiocarcinoma and to show the potential of this receptor as a therapeutic target. 


\title{
R E S U M O
}

\begin{abstract}
Objetivo: avaliar a expressão do receptor do fator de crescimento epitelial (EGFR) por meio de imuno-histoquímica, e verificar sua associação com fatores prognósticos e com a sobrevida dos pacientes operados por colangiocarcinoma. Métodos: a expressão imunohistoquímica de EGFR foi verificada em 35 peças cirúrgicas de colangiocarcinomas (CCA). Curvas de sobrevida foram obtidas pelo método de Kaplan-Meier. Resultados: expressão significativa de EGFR foi encontrada em dez $(28,6 \%)$ de 35 CCA, oito com escore 3 e dois com escore 2. Estágios avançados (III e IV) apresentaram maior expressão de EGFR $(p=0,07)$. As características clínicas que mais estiveram associadas com a expressão positiva de EGFR foram o sexo feminino $(p=0,06)$ e ausência de comorbidades $(p=0,06)$. A sobrevida global aos 12, 24, 36 e 48 meses foi de 100\%, 82,5\%, 59\% e 44,2\%, respectivamente. A sobrevida de pacientes EGFR positivos aos 12, 24, 36 e 48 meses foi de 100\%, 75\%, 50\% e 0\%, enquanto que para EGFR negativos foi de 100\%, 87,5\%, 65,6\% e $65,6 \%$, respectivamente. Conclusão: a expressão do EGFR ocorreu em $28,6 \%$ dos casos estudados e esteve associada a menor sobrevida.
\end{abstract}

Descritores: Colangiocarcinoma. Genes erbB-1. Prognóstico. Análise de Sobrevida.

\section{REFERENCES}

1. Khan SA, Thomas HC, Davidson BR, Taylor-RobinsonSD. Cholangiocarcinoma. Lancet. 2005;366(9493):130314. Erratum in: Lancet. 2006;367(9523):1656.

2. Resende V, Santos JP, Gomes RV, Vidigal PV, Pedrosa MS. Papillary neoplasias of the biliary tract. Rev Col Bras Cir. 2014;41(6):445-50.

3. Castellano-Megías VM, Ibarrola-de Andrés C, ColinaRuizdelgado F. Pathological aspects of so called "hilar cholangiocarcinoma". World J Gastrointest Oncol. 2013;5(7):159-70.

4. Nakanuma Y, Kakuda Y. Pathologic classification of cholangiocarcinoma: new concepts. Best Pract Res Clin Gastroenterol. 2015;29(2):277-93.

5. Tyson GL, El-Serag HB. Risk factors for cholangiocarcinoma. Hepatology. 2011;54(1):173-84.

6. Singal AK, Vauthey JN, Grady JJ, Stroehlein JR. Intra-hepatic cholangiocarcinoma--frequency and demographic patterns: thirty-year data from the M.D. Anderson Cancer Center. J Cancer Res Clin Oncol. 2011; 137(7):1071-78.

7. Huang $Y$, Li X, Zhao Y. Progression of targeted therapy in advanced cholangiocarcinoma. Chin J Cancer Res. 2015;27(2):122-7.

8. Thomas MB. Biological characteristics of cancers in the gallbladder and biliary tract and targeted therapy. Crit Rev Oncol Hematol. 2007;61(1):44-51.

9. Ruys AT, Groot Koerkamp B, Wiggers JK, Klümpen $\mathrm{HJ}$, ten Kate FJ, van Gulik TM. Prognostic biomarkers in patients with resected cholangiocarcinoma: a systematic review and meta-analysis. Ann Surg Oncol. 2014;21(2):487-500.

10. Esnaola NF, Meyer JE, Karachristos A, Maranki $J$, Camp ER, Denlinger CS. Evaluation and management of intrahepatic and extrahepatic cholangiocarcinoma. Cancer. 2016;122(9):1349-69.

11. Harder J, Waiz O, Otto F, Geissler M, Olschewski $M$, Weinhold $B$, et al. EGFR and HER2 expression in advanced biliary tract cancer. World J Gastroenterol. 2009;15(36):4511-7.

12. DeOliveira $\mathrm{ML}$, Cunningham SC, Cameron JL, Kamangar F, Winter JM, Lillemoe KD, et al. Cholangiocarcinoma: thirty-one-year experience with 564 patients at a single institution. Ann Surg.2007;245(5):755-62.

13. Tsukahara $T$, Shimoyama $Y$, Ebata $T$, Yokoyama $Y$, Igami T, Sugawara $G$, et al. Cholangiocarcinoma with intraductal tubular growth pattern versus intraductal papillary growth pattern. Mod Pathol. 2016;29(3):293-301.

14. Faria JAQA, Andrade C, Goes AM, Rodrigues MA, Gomes DA. Effects of different ligands on epidermal growth factor receptor (EGFR) nuclear translocation. Biochem Biophys Res Commun. 2016;478(1):39-45.

15. Sohal DP, Shrotriya S, Abazeed M, Cruise $M$, Khorana A. Molecular characteristics of biliary tract cancer. Crit Rev Oncol Hematol. 2016;107:111-8.

16. Leone F, Cavalloni G, Pignochino Y, Sarotto I, Ferraris $R$, Piacibello $W$, et al. Somatic mutations of epidermal growth factor receptor in bile duct and gallbladder carcinoma. Clin Cancer Res. 2006;12(6):1680-5. 
17. Hoffmann AC, Goekkurt E, Danenberg PV, Lehmann S, Ehninger G, Aust DE, et al. EGFR, FLT1 and heparanase as markers identifying patients at risk of short survival in cholangiocarcinoma. PLoS One. 2013;8(5):e64186.

18. Yang $X$, Wang $W$, Wang $C$, Wang $L$, Yang $M$, Qi $M$, et al. Characterization of EGFR family gene aberrations in cholangiocarcinoma. Oncol Rep. 2014;32(2):700-8.

19. Voss JS, Holtegaard LM, Kerr SE, Fritcher EG, Roberts LR, Gores GJ, et al. Molecular profiling of cholangiocarcinoma shows potential for targeted therapy treatment decisions. Hum Pathol. 2013;44(7):1216-22.

20. Edge SB, Compton CC. The American Joint Committee on Cancer: the 7th edition of the AJCC cancer staging manual and the future of TNM. Ann Surg Oncol. 2010;17(6):1471-4.

21. Blechacz B, Komuta M, Roskams T, Gores GJ. Clinical diagnosis and staging of cholangiocarcinoma. Nat Rev Gastroenterol Hepatol. 2011;8(9):512-22.

22. Yoshikawa D, Ojima H, Iwasaki M, Hiraoka N, Kosuge $T$, Kasai $S$, et al. Clinicopathological and prognostic significance of EGFR, VEGF, and HER2 expression in cholangiocarcinoma. Br J Cancer. 2008;98(2):41825.

23. Chiorean EG, Ramasubbaiah $R, Y u$ M, Picus J, Bufill JA, Tong $Y$, et al. Phase II trial of erlotinib and docetaxel in advanced and refractory hepatocellular and biliary cancers: Hoosier Oncology Group GI06101. Oncologist. 2012;17(1):13.

24. Clapéron A, Mergey $M$, Nguyen Ho-Bouldoires TH, Vignjevic D, Wendum D, Chretien $Y$, et al. EGF/EGFR axis contributes to the progression of cholangiocarcinoma through the induction of an epithelial-mesenchymal transition. J Hepatol. 2014;61(2):325-32.

25. Brivio S, Cadamuro M, Fabris L, Strazzabosco. Epithelial-to-mesenchymal transition and cancer invasiveness: what can we learn from cholangiocarcinoma? J Clin Med. 2015;4(12):202841.

26. Wiggers JK, Ruys AT, Groot Koerkamp B, Beuers $U$, ten Kate FJ, van Gulik TM. Differences in immunohistochemical biomarkers between intraand extrahepatic cholangiocarcinoma: a systematic review and meta-analysis. J Gastroenterol Hepatol. 2014;29(8):1582-94.

27. Ercolani G, Dazzi A, Giovinazzo F, Ruzzenente A, Bassi C, Guglielmi A, et al. Intrahepatic, peri-hilar and distal cholangiocarcinoma: three different locations of the same tumor or three different tumors? Eur J Surg Oncol. 2015;41(9):1162-9.

Received in: 19/02/2018

Accepted for publication: 22/03/2018

Conflict of interest: none.

Source of funding: Foundation for Research Support of the State of Minas Gerais (FAPEMIG), Coordination for Improvement of Higher Education Personnel (CAPES) and National Council for Scientific and Technological Development (CNPQ).

\section{Mailing address:}

Vivian Resende

E-mail: vivianresende.ufmg@gmail.com / vresende@medicina.ufmg.br

(cc) BY 